\title{
Biodegradation of Expanded Polystyrene by Larval and Adult Stages of Tenebrio molitor with Varying Substrates and Beddings
}

\author{
Kevin J. Palmer ${ }^{1} \cdot$ Kerri Lauder $^{1} \cdot$ Kyeshaun Christopher $^{1} \cdot$ Fatima Guerra $^{1}$. \\ Rebecca Welch $^{1}$ - Alex J. Bertuccio ${ }^{1}$ (D)
}

Received: 19 August 2021 / Accepted: 30 November 2021 / Published online: 14 January 2022

(c) The Author(s), under exclusive licence to Springer Nature Switzerland AG 2022

\begin{abstract}
Tenebrio molitor, a species of darkling beetle, is capable of metabolizing expanded polystyrene (EPS), a durable single-use plastic, when in its larval stage, mealworms. EPS consumption studies were conducted on mealworm, beetle, and co-culture habitats with a one-week acclimation period and a three-week experimentation period to compare the EPS consumption rate at each stage. Subsequent experiments tested various beddings (oats, beads), supplemental nutrients (spinach, protein powder paste, cucumbers, lemon slices), and EPS pre-treatments (lemon-lime soda, lemon juice, tomato paste) to determine the effect of those variations on mealworm EPS consumption. It was concluded that one mealworm consumes EPS at least fifty times faster than one beetle. EPS biodegradation rates were estimated under the assumption that $48.2 \%$ of consumed EPS was biodegraded by mealworm gut bacteria into carbon dioxide and biomass. It was found that EPS biodegradation rates increased $34.8 \%$ in habitats with inedible bead beddings compared to those with an edible oat bedding. EPS biodegradation rates by mealworms were also seen to increase $482 \%$ in habitats where the EPS was pre-treated with lemon-lime soda and $125 \%$ in habitats with a spinach supplemental nutrient compared to EPS biodegradation rates in a habitat with no supplemental nutrient or pre-treatment. Each supplemental nutrient and EPS pre-treatment variation in an individual inedible bead bedding improved the mealworm consumption rate of EPS. It was determined that approximately four mealworms could degrade EPS at least as quickly as natural biodegradation. These findings suggest that habitat conditions strongly affect EPS consumption rates by mealworms.
\end{abstract}

\section{Highlights}

- Mealworm consumption rates of EPS are fifty times greater than those of beetles.

- Mealworm EPS consumption rates are lower in edible beddings than inedible beddings.

- EPS consumption rates by T. molitor improved with cups pre-treated in acidic media.

Keywords T. molitor $\cdot$ Mealworm $\cdot$ Expanded polystyrene $\cdot$ Biodegradation $\cdot$ Nutrient $\cdot$ Consumption rate

Alex J. Bertuccio

alex.bertuccio@rutgers.edu

1 Department of Chemical and Biochemical Engineering, Rutgers, The State University of New Jersey, 98 Brett Road, Piscataway, NJ 08854, USA 


\section{Introduction}

The mass generation of plastic waste has become an environmental issue as manufacturing reached 368 million metric tons in 2019 alone (Zalasiewicz et al. 2016; Plastics Europe 2020). Plastic is widely used for packaging as it is inexpensive, lightweight, durable, and moldable (Marsh and Bugusu 2007; Andrady and Neal 2009; Jaiswal et al. 2020; Urbenak et al. 2020). Polystyrene, a common plastic polymer used in packaging, is estimated to make up $7.1 \%$ of annual plastic produced and has been found to degrade at a rate of less than 1\% when in soil for 90 days (Ho et al. 2017; Yang et al. 2018b). Expanded polystyrene (EPS), one trade name is Styrofoam, is often utilized as a single-use plastic and occupies $30 \%$ of landfills by volume (Davis 2019). EPS has a minimum lifespan of 500 years in nature as it is highly resistant to natural degradation (Davis 2019). Traditional disposal methods of EPS result in the generation of environmental pollutant byproducts such as furans, dioxins, and polychlorinated biphenyls (Verma et al. 2016). Plastic waste, like EPS, agglomerates and breaks down in landfills producing leachate and microplastics, which contaminate land, groundwater, and waterways, poisoning the inhabitants and users of the water resources (Thaysen et al. 2018; Cheung et al. 2019). While the level of toxicity depends on the composition of the plastic, leachate and microplastics contamination in an aquatic environment have been shown to interact with the animal endocrine system and lead to decreased growth, reproduction, and feeding, while increasing mortality rates (Franzellitti et al. 2019).

As a result of the environmental impact by plastic waste, alternative methods to degrade or repurpose EPS are being explored. Degradation is one process that has been considered and tested since the 1970s for reducing plastic pollution utilizing bacteria or photooxidation; studies performed over the last fifteen years show that microorganisms and soil invertebrates have the ability to biologically degrade plastics (Albertsson et al. 1987; Chan et al. 2008; Sivan 2011; Yang et al. 2015a; Ahmed et al. 2018; Peng et al. 2019, 2020, 2021; Yang et al. 2021 a, b). Within the past decade, researchers have shown that the larval stage of various members of the darkling beetle species have the ability to biodegrade EPS such as: T. molitor, Tenebrio obscurus, and Zophobas atratus (Yang et al. 2015a; Zhou et al. 2016; Brandon et al. 2018; Peng et al. 2019; Kim et al. 2020; Lear et al. 2021, Yang et al. 2021a). Peng et al. (2019) recorded greater survival rates for T. molitor and T. obscurus when the larvae were fed solely polystyrene than when unfed. Researchers found that the larvae of both $T$. molitor and Z. atratus consumed more polystyrene when provided with wheat bran (Yang et al. 2018b, 2021b; Peng et al. 2019). It was determined that yellow mealworms, T. molitor, could metabolize EPS due to the presence of two species of gut bacteria (Yang et al. 2015a; Brandon et al. 2018; Yang et al. 2018c; Peng et al. 2019; Brandon et al. 2021). The ability of the gut microbial communities found within both $T$. molitor and T. obscurus larvae to depolymerize EPS was significantly reduced when the mealworms were treated with antibiotics, such as gentamicin (Yang et al. 2015b, 2018c; Peng et al. 2019). The gut microbial communities that were isolated and grown in vitro were also ineffective at breaking down EPS and showed no metabolic activity upon interaction with EPS (Yang et al. 2015a). This suggests that the mealworm gut provides bacteria with an environment effective for EPS degradation that cannot be replicated in the lab at this time (Yang et al. 2015b).

Many researchers proposed degradation mechanisms that outline the depolymerization of EPS into carbon dioxide, smaller chain polymers, biomass, and fecula in the gut of the mealworm (Zhou et al. 2016; Brandon et al. 2018: Yang et al. 2018c; Tsochatzis et al. 
2021). Yang et al. (2015a) used a ${ }^{13} \mathrm{C}$ - or $\beta{ }^{13} \mathrm{C}$-labeled polystyrene to perform a carbon mass balance between the consumed polystyrene feedstock and the produced biomass, carbon dioxide and fecula. The researchers found that at least $48.2 \%$ of carbon from consumed EPS is biodegraded into biomass and carbon dioxide (Yang et al. 2015a). The remaining $51.8 \%$ of carbon from consumed EPS is a combination of fecula (49.2\%) and carbon that is unaccounted for (2.6\%) (Yang et al. 2015a). Brandon et al. used a similar carbon mass balance method and determined that approximately $46 \%$ of carbon from consumed EPS was recovered as biomass and carbon dioxide, while the remaining 54\% was recovered as fecula, consistent with the results of Yang et al. (2015a) and Brandon et al. (2018).

Fecula is often analyzed via gel permeation chromatography (GPC), Fourier-transformed infrared spectroscopy (FTIR), thermal gravimetric analysis (TGA) or proton nuclear magnetic resonance ( ${ }^{1} \mathrm{H}-\mathrm{NMR}$ ) (Yang et al. 2018c; Peng et al. 2019). Most analyses focus on the weighted average molecular weight, $\mathrm{M}_{\mathrm{w}}$, and the average molecular weight, $\mathrm{M}_{\mathrm{n}}$, of the fecula which are helpful for determining the molecular weight and length of polymers. Since $\mathrm{M}_{\mathrm{w}}$ and $\mathrm{M}_{\mathrm{n}}$ are measures of molecular weight, GPC is often used to separate molecules by size. Using the GPC spectra and other available data, chemists can use the polymer extracts of any sample to determine the $M_{w}$ and $M_{n}$. Polystyrene is a long chain polymer with an average molecular weight larger than the byproducts of polystyrene biodegradation. Peng et al. (2019) showed that the $M_{w}$ of the fecula was $29.8 \%$ lower than that of the EPS fed to mealworms. Additionally, the $M_{n}$ of the fecula was $11.7 \%$ lower than that of the polystyrene feedstock for Peng et al. (2019). Other studies confirm the decrease in $M_{w}$ and $M_{n}$ when comparing the mealworm fecula to the EPS feedstock (Yang et al. 2015b, 2018c Brandon et al. 2018). This evidence shows that during the mealworm digestive process, the polystyrene is broken down into significantly smaller polymer chains than the polystyrene feedstock being consumed.

GPC analysis of fecula produced by gentamicin-treated mealworms proved that the bacteria in the gut plays a significant role in the biodegradation process (Yang et al. 2015b). The $M_{w}$ and $M_{n}$ of mealworm fecula in a Yang et al. (2015b) study were $20.8 \%$ and $20.2 \%$ lower than that of the polystyrene feedstock, respectively. However, the $M_{w}$ and $M_{n}$ of the fecula from gentamicin-treated mealworms were lower than the EPS feedstock by $1.42 \%$ and $2.00 \%$, respectively (Yang et al. 2015b). The gentamicin decreased the effectiveness of the bacteria in the mealworm gut 10 -fold, confirming the role bacteria play in EPS biodegradation.

FTIR analyses of mealworm fecula samples by Yang et al. (2018c) and Peng et al. (2019) provide further evidence of polystyrene degradation. The fecula FTIR spectra showed weaker peaks in the $625 \mathrm{~nm}$ to $970 \mathrm{~nm}$ range compared to those of the polystyrene feedstock, indicating fewer ring bending vibrations that are present in many polystyrene samples. Additionally, the fecula samples showed fewer benzene peaks, and more carbonyl and alkene peaks than polystyrene. This is evidence that the benzene rings in the polystyrene were likely broken and depolymerized during the biodegradation process, confirming that biodegradation of polystyrene takes place in the mealworm gut (Yang et al. 2018c; Peng et al. 2019).

Peng et al. (2019) utilized TGA to examine the fecula of T. molitor. During the TGA process, the mass of the sample and the temperature were recorded continuously. The temperature increase from low to high temperatures (e.g., $40{ }^{\circ} \mathrm{C}-800{ }^{\circ} \mathrm{C}$ ), during which parts of the sample undergo a pyrolysis reaction which produces combustible gases and biochar (charcoal produced from biomass). The production of combustible gases decreases the mass of a sample, creating a "mass-loss." The different chemicals and components in a sample will undergo pyrolysis at different temperatures, creating a unique TGA spectra that 
creates a temperature and mass-loss profile for each sample. The change in mass can also be measured as a mass-loss ratio: the ratio of mass lost in each given temperature range to the initial mass of the sample. The mass-loss ratio was used to compare the TGA spectra of the fecula of T. molitor to the TGA spectra of the polystyrene feedstock for the mealworms as polystyrene undergoes pyrolysis in a specific temperature range. Peng et al. (2019) found that the polystyrene fed to the mealworms lost approximately $96.32 \%$ of its mass in the temperature range between $360{ }^{\circ} \mathrm{C}$ and $480{ }^{\circ} \mathrm{C}$. However, the mass-loss ratio of the mealworm fecula was only $41.03 \%$ in the same temperature range indicating that the mealworm fecula had a significantly lower long-polymer concentration, and therefore, a lower polystyrene concentration than the feedstock (Peng et al. 2019). Additionally, approximately $25 \%$ of the fecula underwent pyrolysis in the $40{ }^{\circ} \mathrm{C}-360{ }^{\circ} \mathrm{C}$ temperature range compared to approximately $3 \%$ for the polystyrene fed to the mealworms (Peng et al. 2019). This is expected as the most likely components to undergo pyrolysis in that range include gut secretion, carboxylic acids, other biological wastes and biodegradation residue, that is not polystyrene (Peng et al. 2019). The evidence obtained from the TGA spectra show that while there is EPS biodegradation occurring in the mealworm gut, and byproducts are present in the fecula, there is still some polystyrene present in the fecula that is not broken down. The exact composition of the fecula remains unknown. Using the results obtained from the TGA, GPC, and FTIR spectra for the mealworm fecula samples, compared to the polystyrene feedstock, it is shown that the mealworm fecula is not just polystyrene, but instead a mix of polystyrene, smaller polymer chains, biological matter, and other byproducts (Yang et al. 2015a, b, 2018b; Peng et al. 2019).

Currently, researchers have focused on the ability of the larval stage of $T$. molitor to break down EPS without examining environmental and nutritional parameters such as the impact of artificial/natural beddings, the effect of added supplemental nutrients other than bran, and EPS pre-treatments (Jung et al. 2014; Yang et al. 2015a, 2018a, 2021c; Urbenak et al. 2020). Information is also limited on the ability of the adult stage to consume EPS and if the presence of beetles in a co-culture, a habitat consisting of both mealworms and beetles, will affect mealworm EPS consumption. In this study, the authors investigated the effects of various co-nutrients other than bran, beddings, and EPS pre-treatments on the consumption rate of EPS by mealworms, as well as compared the EPS consumption rates of the larval and adult form of T. molitor alone and in a co-culture. The authors aim to identify which habitat conditions and preparations can be beneficial for mealworm EPS consumption.

\section{Materials and Methods}

\subsection{Habitat Layout Variations}

Each habitat was contained in a $33 \mathrm{~cm} \times 20 \mathrm{~cm} \times 13 \mathrm{~cm}$ polypropylene container (Sterilite) with 25 holes, $4 \mathrm{~mm}$ in diameter, drilled into the removable top. A standard habitat contained a $30 \mathrm{~mL}$ EPS cup (Kirkland), one petri dish with 25-30 g of oats (Quaker Oats) and another petri dish with a damp, flattened paper towel. Tap water was used to wet paper towels. The beddings tested were $150 \mathrm{~g}$ of low-density polyethylene beads (Perler) and $150 \mathrm{~g}$ of oats (Quaker Oats). Pre-treated cups were fully soaked in either lemon-lime soda (Sprite), lemon juice (Realemon) or tomato paste (Hunt's). Cups treated with lemon-lime soda or lemon juice were soaked for $48 \mathrm{~h}$ and dried overnight. 
The tomato paste pre-treatment was spread heavily on the cup and wiped off after $24 \mathrm{~h}$. Bead bedding habitats consisted of 100 mealworms with varied supplemental nutrients of $5 \mathrm{~g}$ cucumber (Pero Family Farms), $5 \mathrm{~g}$ protein powder (Orgain) with $2 \mathrm{~g}$ water in a paste, $5 \mathrm{~g}$ spinach (Good \& Gather), or no supplemental nutrient. Additional bead beddings were comprised of 100 beetles or a co-culture of 50 beetles and 50 mealworms. All three pre-treatment habitats utilized a bead bedding as well. Oat bedding habitats had 100 mealworms and varied supplemental nutrients of $5 \mathrm{~g}$ cucumber (Pero Family Farms), $5 \mathrm{~g}$ spinach (Good \& Gather), $5 \mathrm{~g}$ lemon slice (Dole), 5 g protein powder (Syntha6 Edge) with $2 \mathrm{~g}$ water in a paste, or no supplemental nutrient. All mealworms used were approximately $2 \mathrm{~cm}$ in length. Each habitat was tested in triplicate over the span of four weeks. All recorded consumption rates were decreased by $5 \%$ as not all EPS removed from the cup is consumed. Some morsels fell to the bottom of the habitat. Yang et al. (2015a) estimates 3 to $5 \%$ of the EPS removed from the cup is not ingested based on a ${ }^{13} \mathrm{C}$ - or $\beta{ }^{13} \mathrm{C}$-labeled carbon mass balance performed on the system. Cup masses were recorded at least three days per week for the entirety of the experiment. EPS cup masses for pre-treated cups were recorded before and after the pre-treatment process in order to determine the added mass resulting from the pre-treatment.

\subsection{Maintenance}

Habitats were adjusted every 3 to 5 days. Each EPS cup was weighed on an electronic balance (Toprime) with an accuracy of $\pm 0.01 \mathrm{~g}$ during each adjustment period, and habitats were replenished with water and fresh nutrients. To maintain a constant total of $T$. molitor at the proper stage, pupae and dead larvae were replaced with live mealworms while dead beetles were replaced with live beetles. Four stock bins, one for each life stage, were maintained every 4 to 7 days. Pupae found in the larvae stock bin were moved into the pupae stock bin, and adolescent beetles in the pupae stock bin were transferred to the beetle stock bin. Every 30 days, the eggs in the beetle stock bin were harvested by removing all beetles and placing the remaining oats and eggs in a separate container. Hatched mealworms were transferred to the larval stock bin once they reached an appropriate size of approximately $1 \mathrm{~cm}$. Habitats were kept in a minimally lit room with an approximate temperature range of $25 \pm 5{ }^{\circ} \mathrm{C}$. After habitats were setup, mealworms were given a one-week acclimation period in the new environment. Mealworms replaced after the initial setup did not receive an additional acclimation period.

Due to COVID-19 restrictions, some experiments were relocated to an at-home setting. At-home experimentation led to some variable conditions such as temperature and humidity, which can affect $T$. molitor eating habits and mobility; colder temperatures result in the mealworms moving slower and eating less, whereas warmer environments lead to quicker pupation (Yang et al. 2015a; Bjørge et al. 2018). Without the controlled and constant environment provided by the lab, the EPS consumption rates for at-home experiments had observable changes when compared to experiments conducted in the lab. However, on a week-by-week basis for at-home experiments, there were no noticeable changes, indicating a consistent setting for at-home conditions. At-home and in lab experimental results are not directly compared within this paper. All experimental data collected was from at-home experimentation with the exception of the following in which experimentation took place in a regulated lab: a bead bedding with worms, an oat bedding with worms, a co-culture in a bead bedding, and a bead bedding with beetles. 


\section{Results and Discussion}

\subsection{EPS Consumption by Lifecycle Stage}

In three weeks, bead habitats containing 100 mealworms, a co-culture of 50 mealworms and 50 beetles, and 100 beetles consumed $26.8 \%, 15.3 \%$, and $0.59 \%$, by weight, of the EPS cup, respectively. An increased number of live mealworms present in a habitat led to an increase in net EPS consumption. The daily consumption trends are shown in Fig. 1. Table 1 shows EPS consumption rates, under the assumption that $5 \%$ of the EPS consumed fell to the bottom of the habitat in the eating process and was not actually consumed (Yang et al. 2015a). The estimated EPS degradation rate in Table 1 assumes a $48.2 \%$ degradation of consumed polystyrene based on the carbon mass balance data provided by Yang et al. (2015a). This estimate is likely conservative as it is made under the assumption that the fecula is identical in composition to the polystyrene feedstock, which is known to be false through the use of analytical evidence on mealworm fecula and polystyrene feedstock (Yang et al. 2015a, 2018b; Peng et al. 2019). However, 48.2\% of consumed EPS being biodegraded is the best estimate available, and the actual EPS biodegradation rates for the experiments will likely be higher than those suggested in Table 1. Chronological photos of EPS cup consumption by mealworms over five weeks in a representative oat bedding are shown in Supplementary Material (SM) Fig. SM1.

In the mealworm habitat, the average consumption rate of EPS by a single mealworm was $0.21 \pm 0.02 \mathrm{mg} / \mathrm{d}$, while the beetle habitat had an average EPS consumption rate per beetle of $0.00 \pm 0.01 \mathrm{mg} / \mathrm{d}$. The beetles mostly consumed the hard, protective outer layer of the EPS cup (Fig. 2a), while the mealworms focused on consuming the softer and less

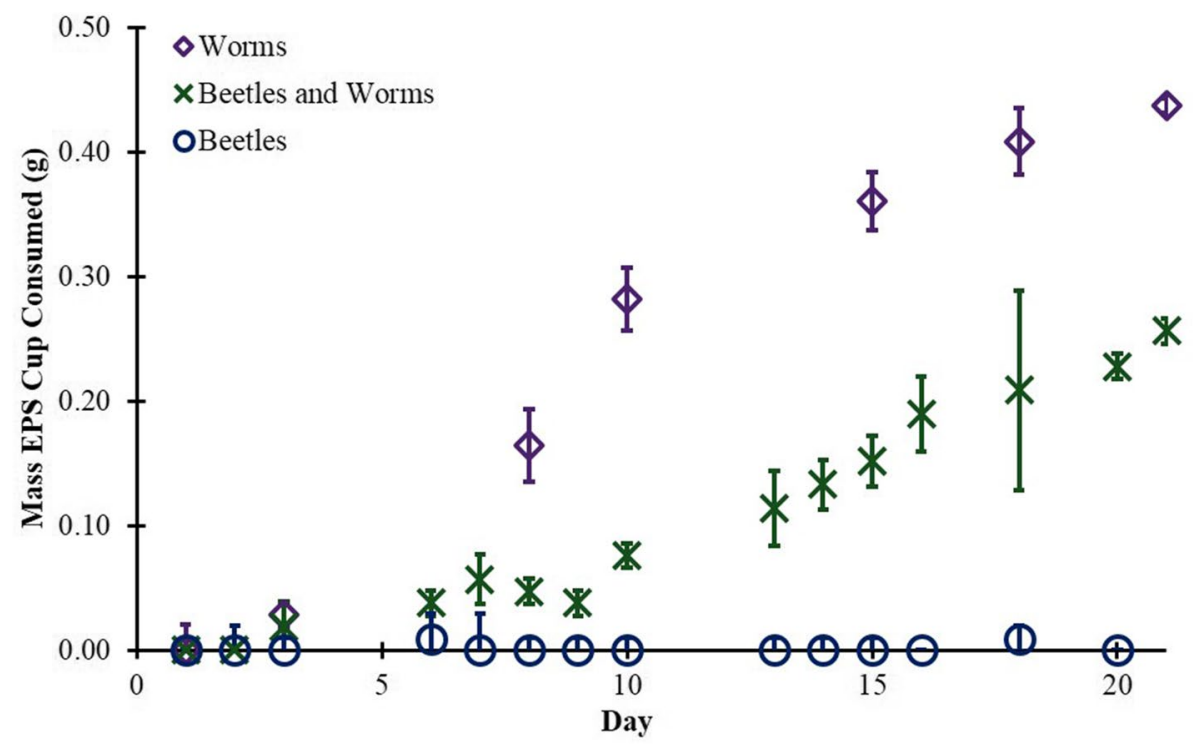

Fig. 1 EPS consumption by 100 mealworms (purple diamonds), 50 mealworms and 50 beetles (green crosses), and 100 beetles (blue circles), all in bead bedding. These studies were conducted in a regulated lab. Error bars represent one standard deviation of triplicate samples 
Table 1 Average EPS Consumption Rate and Estimated EPS Degradation Rate for each experimental setup after the 7-day acclimation period

\begin{tabular}{llll}
\hline Life-Stage & $\begin{array}{l}\text { Supplemental Nutrient (SN) } \\
\text { or Pre-Treatment (PT) }\end{array}$ & $\begin{array}{l}\text { Average EPS Consumption } \\
\text { Rate (mg/Life-Stage/day) }\end{array}$ & $\begin{array}{l}\text { Estimated }{ }^{\Delta} \text { EPS Biodegra- } \\
\text { dation Rate (mg/Life-Stage/ } \\
\text { day) }\end{array}$ \\
\hline
\end{tabular}

\begin{tabular}{llll}
\hline Bead Bedding & & & \\
Mealworm & N/A & $0.03 \pm 0.02$ & $0.02 \pm 0.01$ \\
Mealworm & N/A* & $0.21 \pm 0.02$ & $0.10 \pm 0.01$ \\
Beetle & N/A* & $0.00 \pm 0.01$ & $0.00 \pm 0.00$ \\
Co-Culture & N/A* & $0.24 \pm 0.02$ (mealworm) & $0.12 \pm 0.01$ (mealworm) \\
& & $0.00 \pm 0.01$ (beetle) & $0.00 \pm 0.00$ (beetle) \\
Mealworm & Spinach (SN) & $0.07 \pm 0.02$ & $0.04 \pm 0.01$ \\
Mealworm & Protein Powder Paste $(\mathrm{SN})$ & $0.06 \pm 0.02$ & $0.03 \pm 0.01$ \\
Mealworm & Cucumber (SN) & $0.05 \pm 0.01$ & $0.02 \pm 0.00$ \\
Mealworm & Tomato Paste ${ }^{\#}(\mathrm{PT})$ & $0.14 \pm 0.02$ & $0.07 \pm 0.01$ \\
Mealworm & Lemon-Lime Soda ${ }^{*}(\mathrm{PT})$ & $0.18 \pm 0.01$ & $0.09 \pm 0.00$ \\
Mealworm & Lemon Juice ${ }^{\#}(\mathrm{PT})$ & $0.12 \pm 0.01$ & $0.06 \pm 0.00$ \\
Oat Bedding & & & $0.02 \pm 0.01$ \\
Mealworm & N/A & $0.04 \pm 0.01$ & $0.08 \pm 0.01$ \\
Mealworm & N/A* & $0.16 \pm 0.02$ & $0.01 \pm 0.01$ \\
Mealworm & Cucumber (SN) & $0.03 \pm 0.01$ & $0.03 \pm 0.01$ \\
Mealworm & Lemon Slice (SN) & $0.07 \pm 0.01$ & $0.05 \pm 0.01$ \\
Mealworm & Protein Powder Paste (SN) & $0.10 \pm 0.02$ & \\
\hline
\end{tabular}

*Trials were performed in a regulated lab. Trials without asterisks were performed at home in a consistent setting as the Rutgers University Chemical Engineering Lab was closed due to COVID-19 protocols

$\&$ Co-culture refers to an experimental set-up of 50 mealworms and 50 beetles. All other experimental setups contained 100 of the indicated life-stage

${ }^{\Delta}$ Estimated biodegradation rate is $48.2 \%$ of the average EPS consumption rate. This conversion was determined by Yang et al. (2015a)

\# Assumptions made for pre-treatment analysis include all added mass being consumed in the four-week period, and the ratio of cup mass consumed to added mass consumed remained constant for the duration of the four-week period

dense material beneath the protective layer (Fig. 2b) (Tsochatzis et al. 2021). This observation is consistent with Yang et al. (2015a) with regard to mealworm consumption of polystyrene blocks. A mealworm has a similar life cycle to a caterpillar, which consumes between $4 \%$ and $6 \%$ of its body weight every hour during its larval stage (Kingsolver 2000). T. molitor larvae have been observed to metabolize at approximately 9.85 and 4.89 times the rate of their adult counterparts in low and high protein environments respectively (Urrejola et al. 2011). T. molitor larvae likely consume more than their beetle counterpart since the larvae are preparing for metamorphosis during the pupal stage. This is evident by the mealworms consuming fifty times the mass of EPS daily compared to beetles. When beetles and mealworms were combined in the co-culture habitats, the average mealworm consumption rate of EPS was $0.24 \pm 0.02 \mathrm{mg} / \mathrm{d}$, which is slightly higher than the $0.21 \pm 0.02 \mathrm{mg} / \mathrm{d}$ in mealworm-only habitats. This co-culture mealworm EPS consumption rate was calculated by utilizing the beetle EPS consumption rate to estimate the amount of EPS consumed by beetles, subtracting that value from total consumed EPS, and using the difference to determine the mealworm EPS consumption rate for the fifty mealworms in the 

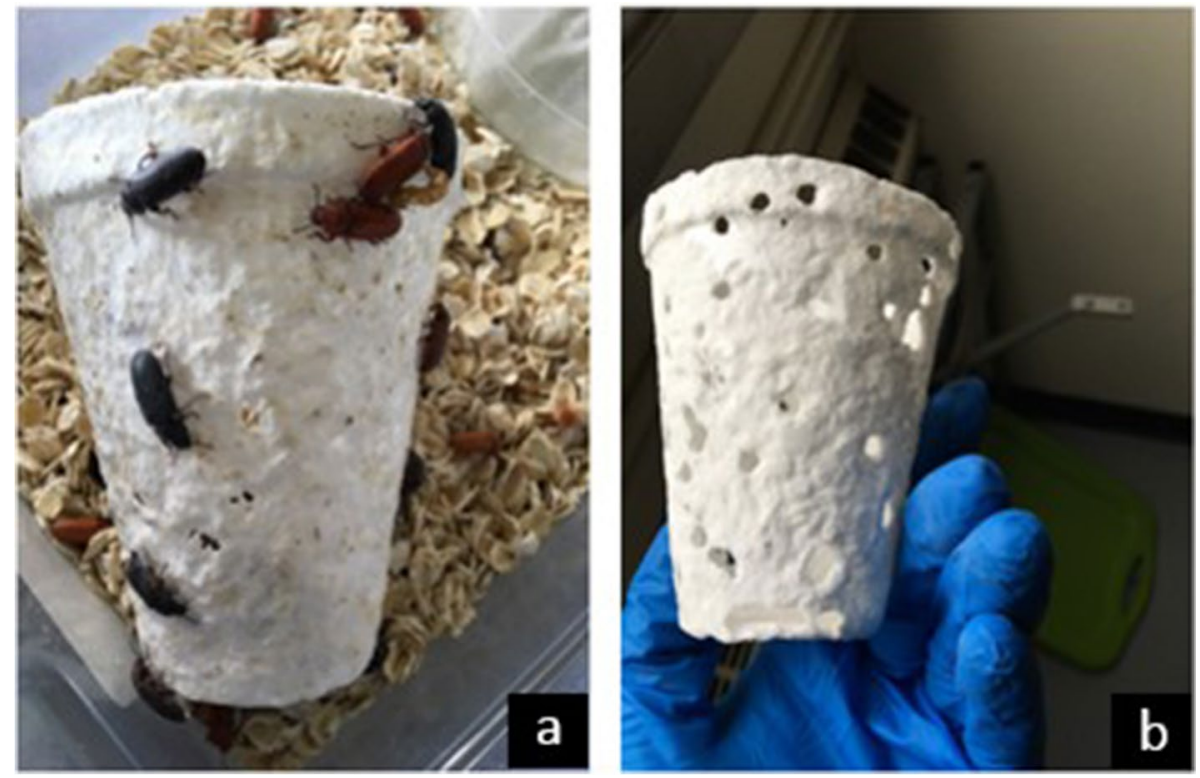

Fig. 2 a EPS cup consumed by beetles. b EPS cup consumed by mealworms. These studies were conducted in a regulated lab

habitat. Although the difference in the two mealworm EPS consumption rates was not statistically significant, it is possible that the presence of beetles increases EPS consumption by mealworms. Beetles in a co-culture potentially expose a larger area of softer EPS, which could increase EPS consumption rates by mealworms. However, there may be additional interactions between the mealworms and beetles which could affect EPS consumption.

Prior studies show that an EPS cup can be degraded at rates of 3\% over four months in nature - the equivalent of $0.43 \mathrm{mg} / \mathrm{d}$ of the EPS cups used in this experiment (Yang et al. 2018b). Using the conservative $48.2 \%$ consumed EPS degradation estimate provided by Yang et al. (2015a, 2018b) in both the mealworm-only and the co-culture habitats with a bead bedding and no supplemental nutrient, the degradation rates for a single mealworm would be $0.10 \pm 0.02 \mathrm{mg} / \mathrm{d}$ and $0.12 \pm 0.02 \mathrm{mg} / \mathrm{d}$, respectively. Based on this conservative estimate, it is probable that four mealworms are capable of matching, or exceeding, natural EPS degradation. For every additional mealworm added to the habitat, the total consumption of EPS was seen to increase during the 21-day trial. However, it is not known if individual consumption rates remain consistent as more larvae are added to the habitat.

\subsection{Effect of Varying Beddings, Nutrients and Pre-Treatments on EPS Consumption}

The average EPS consumption by a single mealworm in habitats with a bead bedding was $0.21 \pm 0.02 \mathrm{mg} / \mathrm{d}$, while a single mealworm consumed $0.16 \pm 0.03 \mathrm{mg} / \mathrm{d}$ of EPS in habitats with an oat bedding. The daily consumption of EPS with various beddings are shown in Fig. 3. Habitats with a plastic bead bedding had the highest EPS consumption rate over the 21-day period. The bead bedding is inedible and was considered a low-protein environment, as the only consumable options for the mealworms were EPS and oats in a small 


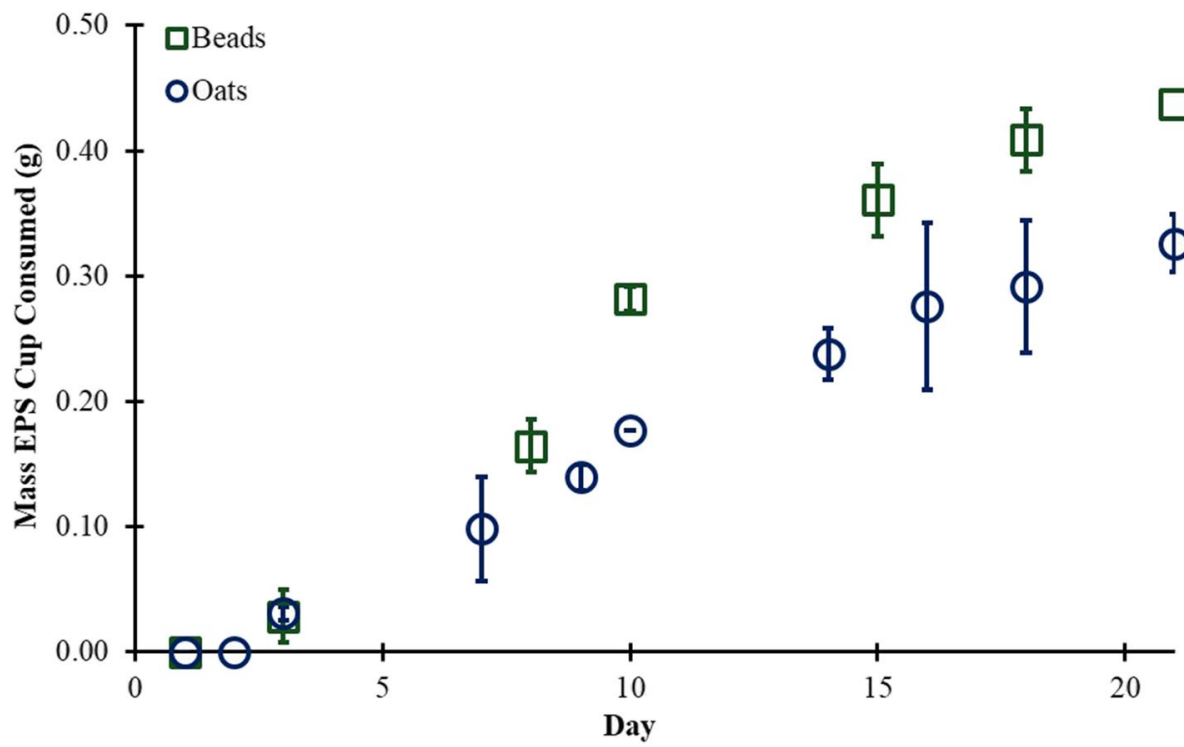

Fig. 3 EPS consumption by 100 mealworms in a bead bedding (green triangles) and oat bedding (blue circles) with no supplemental nutrient. These studies were conducted in a regulated lab. Error bars represent one standard deviation of triplicate samples

petri dish. The oat bedding was considered a protein-rich environment, as it provided the mealworms with easy access to high concentrations of a nutrient-rich food in the habitat (van Broekhoven et al. 2015). Mealworms in the bead bedding followed a similar trend to caterpillars, which have been shown to consume food faster in a low-protein environment than in a protein-rich environment (Woods 1999).

EPS consumption by T. molitor was affected by the presence of supplemental nutrients. In an oat bedding, with either cucumber, no nutrient, lemon slice, or protein powder paste, average EPS consumption rates per mealworm were $0.03 \pm 0.01,0.04 \pm 0.01,0.07 \pm 0.01$, and $0.10 \pm 0.02 \mathrm{mg} / \mathrm{d}$, respectively. The daily consumption in habitats with various supplemental nutrients can be seen in Fig. 4. Protein powder paste increased consumption the most in oat bedding habitats, while cucumber did not have a significant effect on EPS consumption. The supplemental nutrients in a bead bedding of no nutrient, cucumber, protein powder paste, and spinach produced average mealworm EPS consumption rates of $0.03 \pm 0.02,0.05 \pm 0.01,0.06 \pm 0.02,0.07 \pm 0.02 \mathrm{mg} / \mathrm{d}$, respectively, as seen in Fig. 5 . It is assumed that the small amount of supplemental nutrient does not have a significant impact on the protein concentration of the habitat. The increased consumption rates suggest that supplemental nutrients provide additional benefits to mealworm diets. This is consistent with studies conducted by Peng et al. (2019) and Yang et al. (2018c) which note significant increases in habitats with a bran co-nutrient compared to those with only polystyrene. Further, Tsochatzis et al. (2021) found that in habitats with water and bran co-nutrients, the presence of monomers and oligomers in the frass was lower than that of habitats with just a bran co-nutrient. This indicates that the consumption of water is beneficial for the degradation of polystyrene, with one possibility being that it aids in the growth of the $T$. molitor gut bacteria utilized in the biodegradation process. All of the co-nutrients used in these experiments had a high water content (spinach, lemon slice, protein powder paste, 


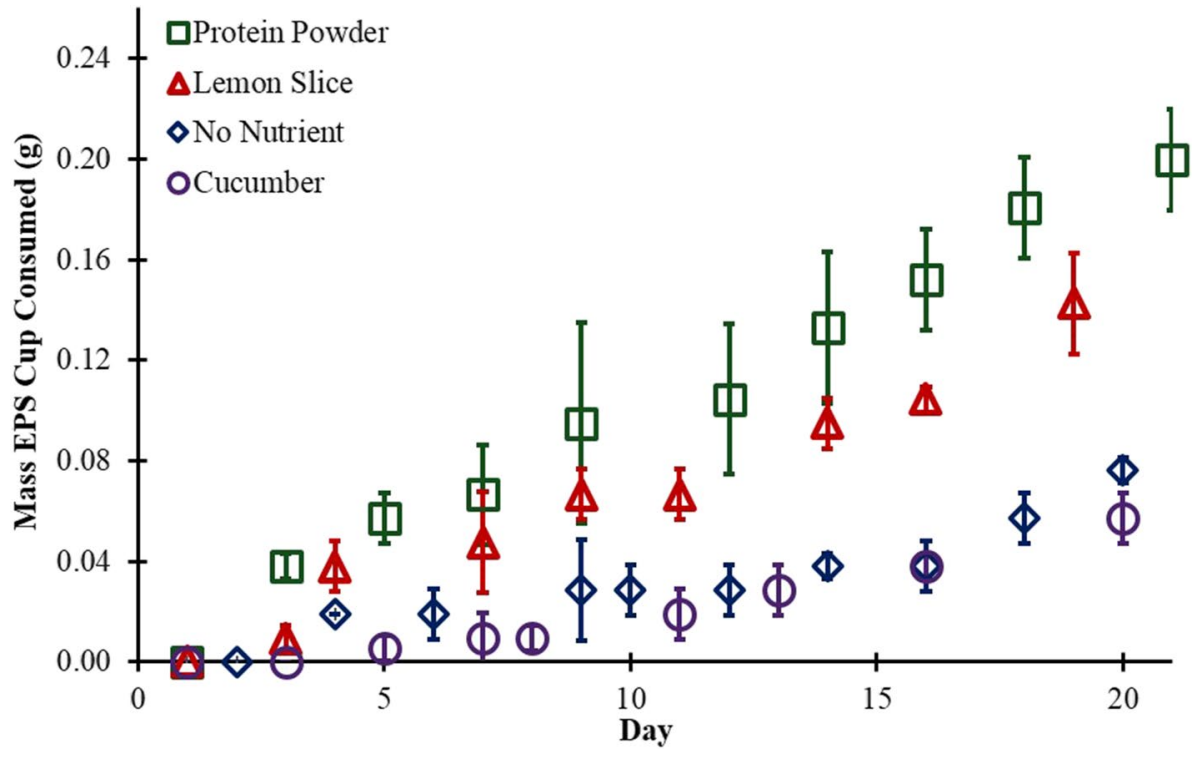

Fig. 4 EPS consumption by 100 mealworms in a bedding of oats with protein powder (green squares), cucumber (purple circles), no nutrient (blue diamonds), and lemon slice (red triangles). These studies were conducted in an at-home setting. Error bars represent one standard deviation of triplicate samples

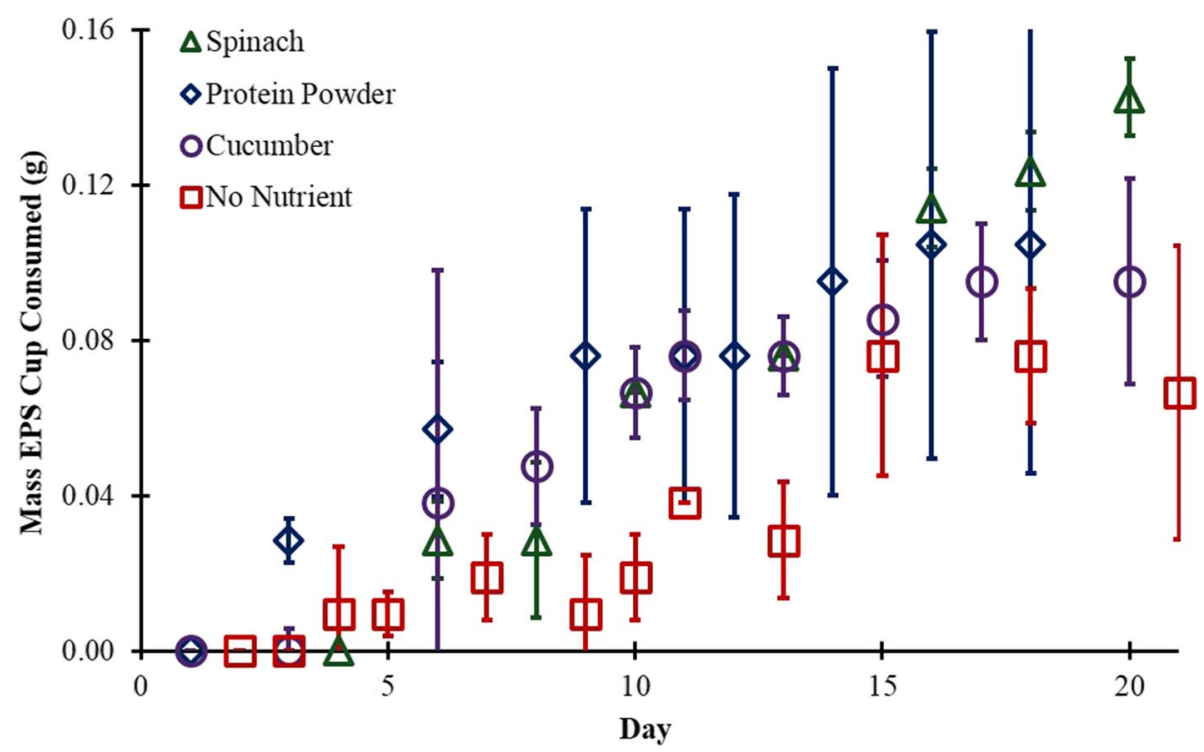

Fig. 5 EPS consumption by 100 mealworms in a bead bedding with spinach (green triangles), protein powder (blue diamonds), cucumber (purple circles) and no supplemental nutrient (red squares). These studies were conducted in an at-home setting. Error bars represent one standard deviation of triplicate samples 
cucumber), leading to increased degradation rates along with increased consumption rates. Sometimes the mealworms struggled to move between the nutrient and the bedding. Often, when mealworms accessed the supplemental nutrient, they did not return to the bedding until the next bin adjustment. Easier access may improve the consumption rates.

All of the tested pre-treatments increased the consumption of EPS when compared to an untreated EPS cup as shown in Fig. 6. Since the pre-treatments added mass to the cups, two assumptions were made to account for the additional mass. The first assumption is that all added mass was consumed by the end of the four-week window including the acclimation period. The added cup mass for the lemon-lime soda, lemon juice and tomato paste pre-treatments were $0.02 \pm 0.00 \mathrm{~g}, 0.07 \pm 0.01 \mathrm{~g}, 0.20 \pm 0.02 \mathrm{~g}$, respectively. The second assumption is that the ratio of cup consumed to added mass consumed remains constant for the duration of the four-week period. For example, a pre-treated cup in a mealworm habitat loses $0.62 \mathrm{~g}$ of mass over the four-week period. If $0.44 \mathrm{~g}, 71 \%$ of that initial cup mass, was consumed during the three-week experimentation period, then it was assumed $71 \%$ of the added mass was also consumed during the three-week experimentation period. The total mass of EPS consumed during the experimentation period is found by taking the difference between $0.44 \mathrm{~g}$ and $71 \%$ of the added mass. This consumed EPS mass was then used to calculate the consumption rates on a mass per mealworm per day basis. The average consumption rates of an EPS cup with no pre-treatment, and EPS cups pre-treated with lemon juice, tomato paste, and lemon-lime soda in a bead bedding was $0.03 \pm 0.01,0.12 \pm 0.01$, $0.14 \pm 0.01,0.17 \pm 0.02 \mathrm{mg} / \mathrm{d}$ per mealworm, respectively (Fig. 6). If a different assumption was made that either all of the added mass, or none of the added mass was consumed during the three-week experimentation period, the range of consumption rates for one mealworm in each pre-treatment would be $0.11-0.14,0.11-0.21$, and $0.17-0.18 \mathrm{mg} / \mathrm{d}$ for the

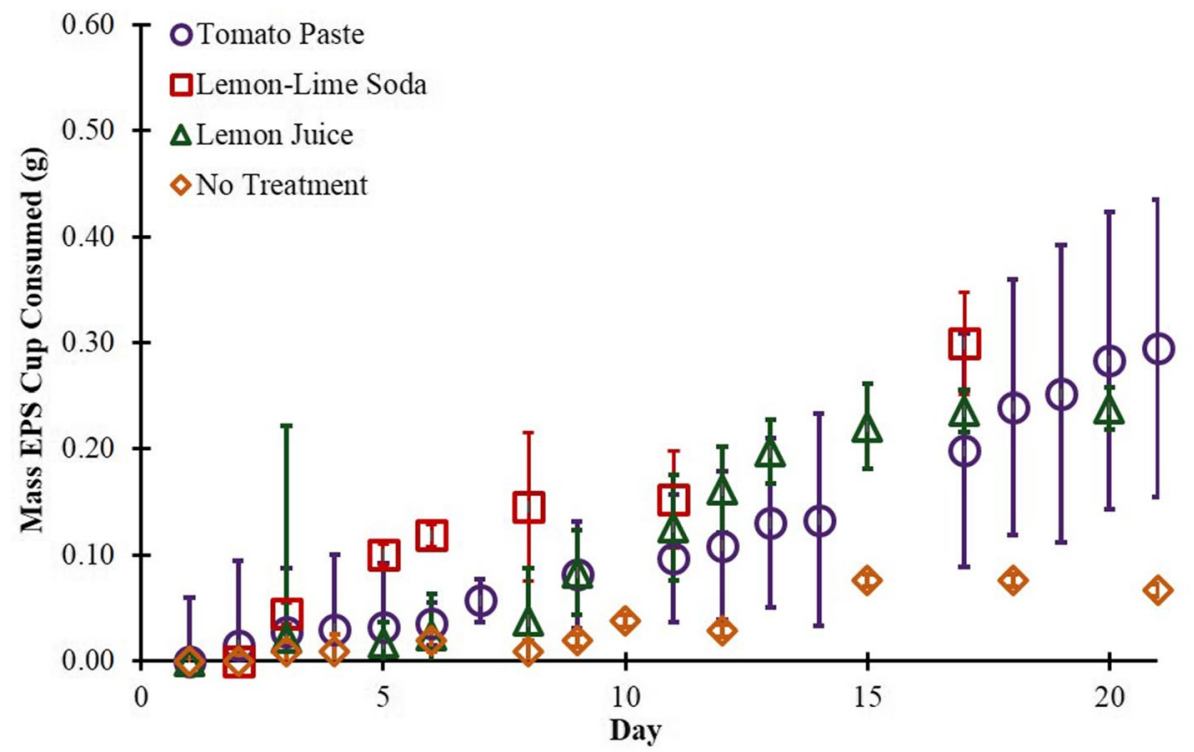

Fig. 6 EPS consumption by 100 mealworms in a bead bedding with tomato paste (purple circles), sprite (red squares), lemon juice (green triangles) and no pre-treatment (orange squares). These studies were conducted in an at-home setting. Error bars represent one standard deviation of triplicate samples. Assumptions made include all added mass being consumed in the four-week period, and the ratio of cup mass consumed to added mass consumed remaining constant for the duration of the four-week period 
lemon juice, tomato paste, and lemon-lime soda pre-treatments, respectively. The low end of the range for all pre-treated EPS mealworm consumption rate ranges are significantly higher than the mealworm EPS consumption rate for an EPS cup with no pre-treatment. This indicates that regardless of added mass, pre-treated EPS cups were consumed much faster than EPS cups with no pre-pretreatment. The lemon-lime soda EPS pre-treatment resulted in the highest consumption rates. It is hypothesized that the high acidity of the pre-treatments weakened the hard outer layer of the EPS cup allowing the mealworms to consume EPS at a faster rate. It is also possible that the pre-treatments provided an additional nutrient source on the EPS cup resulting in increased consumption due to increased activity on and around the cup.

\subsection{Future Considerations}

T. molitor has demonstrated that EPS consumption rates and biodegradation rates can improve in the short-term under the right conditions. Yang et al. (2018c) show that survival rates for habitats with just polystyrene, and polystyrene with a bran co-nutrient are over 95\% after 35 days. However, the survival rate after 98 days for habitats with polystyrene and with polystyrene and bran co-nutrient drop to $11.5 \%$ and $81.5 \%$, respectively (Yang et al. 2018c). The presence of bran significantly affected the survival rate; it is unknown if the presence of other co-nutrients, perhaps those with more nutritional value, would increase the survival rate even further. Rho and Lee (2016) have observed that the lifespan and reproductive output of $T$. molitor is affected by the ratio of proteins to carbohydrates in their diet. Malnutrition and increased death rates have also been seen in other insect species, such as caterpillars and grasshoppers, raised in low-protein environments for long periods of time (Woods 1999; Le Gall and Behmer 2014). There is potential to expand upon the effect of beddings, pre-treatments, and supplemental nutrients discussed in this study, including but not limited to using carrots or lettuce as nutrients, more acidic pre-treatments, and dirt as a bedding. Additionally, there has been no research performed on the mealworm and beetle co-culture to determine if there is chemical signaling that increases EPS consumption, such as a released aggregate pheromone. Despite these uncertainties, mealworms show potential to diminish EPS waste in landfills.

\section{Conclusions}

In habitats containing an inedible bead bedding, without a supplemental nutrient or EPS pre-treatment, a single mealworm can biodegrade EPS at a rate equivalent to 25-30\% that of natural EPS degradation. Bead habitats were the most effective bedding for short term EPS consumption as they had significantly higher mealworm EPS consumption rates than the oat habitats. Habitats consisting of supplemental nutrients often led to increased EPS consumption over those without supplemental nutrients. Supplemental nutrients such as lemon slices, protein powder paste and spinach increased consumption rates the most. Acidic pre-treatments of tomato paste, lemon-lime soda, and lemon juice all greatly improved EPS consumption rates over habitats in which the EPS cup was not pre-treated. Beetles were shown to be ineffective for EPS consumption, but potentially offer aide to mealworm consumption; one beetle consumed fifty times less EPS than one mealworm under the same conditions. Mealworms, and their gut bacteria, appear to offer a safe 
approach to consuming and degrading EPS more efficiently than nature can. Until an alternative biodegradable material is engineered to replace EPS, environmental conditions affecting mealworm consumption of EPS should be further studied to elucidate the potential of $T$. molitor to reduce EPS waste.

Supplementary Information The online version contains supplementary material available at https://doi. org/10.1007/s40710-021-00556-6.

Acknowledgements This project has been generously supported with equipment and materials by the Department of Chemical and Biochemical Engineering at Rutgers University - New Brunswick. Research members Bright Nwanze and Isaac Schiftic assisted in habitat adjustments during some of the experiments.

Authors' Contributions All authors contributed to the study conception and design as well as the material preparation, data collection, and analysis. The manuscript was written and edited by all authors. All authors have read and approved the final manuscript.

Conceptualization: Alex Bertuccio, Kevin Palmer; Methodology: Kevin Palmer, Kerri Lauder, Fatima Guerra, Kyeshaun Christopher, Rebecca Welch, Alex Bertuccio; Formal analysis and investigation: Kevin Palmer, Kerri Lauder, Fatima Guerra, Kyeshaun Christopher, Rebecca Welch; Writing - Review and editing: Kevin Palmer, Kerri Lauder, Fatima Guerra, Kyeshaun Christopher, Rebecca Welch, Alex Bertuccio; Funding acquisition: Alex Bertuccio; Supervision: Alex Bertuccio.

Data Availability The complete datasets generated during this study are available from the corresponding author on reasonable request.

Code Availability Not applicable.

\section{Ethics declarations}

Consent to Participate/ Consent for Publication All authors consent for the publication of the current manuscript presented, including the names and order of authors.

Conflicts of Interest/Competing Interests All authors confirm that they have no affiliations with any organization or entity with any financial or non-financial interest in the subject matter or materials discussed in this study.

\section{References}

Ahmed T, Shahid M, Azeem F, Rasul I, Shah A, Noman M, Hameed A, Manzoor N, Manzoor I, Muhammad S (2018) Biodegradation of plastics: current scenario and future prospects for environmental safety. Environ Sci Pol 25:7287-7298. https://doi.org/10.1007/s11356-018-1234-9

Albertsson AC, Andersson SO, Karlsson S (1987) The mechanism of biodegradation of polyethylene. Polym Degrad Stab 18:73-87. https://doi.org/10.1016/0141-3910(87)90084-X

Andrady AL, Neal MA (2009) Applications and societal benefits of plastics. Philos Trans R Soc B 364:1977-1984. https://doi.org/10.1098/rstb.2008.0304

Bjørge JD, Overgaard J, Malte H, Gianotten N, Heckmann LH (2018) Role of temperature on growth and metabolic rate in the tenebrionid beetles Alphitobius diaperinus and Tenebrio molitor. J Insect Physiol 107:89-96. https://doi.org/10.1016/j.jinsphys.2018.02.010

Brandon AM, Gao SH, Tian R, Ning D, Yang SS, Zhou J, Wu WM, Criddle CS (2018) Biodegradation of polyethylene and plastic mixtures in mealworms (larvae of Tenebrio molitor) and effects on the gut microbiome. Environ Sci Technol 52(11):6526-6533. https://doi.org/10.1021/acs.est.8b02301

Brandon AM, Garcia AM, Khlystov NA, Wu WM, Criddle CS (2021) Enhanced bioavailability and microbial biodegradation of polystyrene in an enrichment derived from the gut microbiome of Tenebrio molitor (mealworm larvae). Environ Sci Technol 55(3):2027-2036. https://doi.org/10.1021/ acs.est.0c04952

Chan JCY, Burugapalli K, Kelly JL, Pandit AS (2008) 12- influence of clinical application on bioresorbability: host response. In: Buchanan F (ed) Degradation rate of Bioresorbable materials. Woodhead Publishing, Cambridge, pp 267-318. https://doi.org/10.1533/9781845695033.5.267 
Cheung PK, Hung PL, Fok L (2019) River microplastic contamination and dynamics upon a rainfall event in Hong Kong, China. Environmental Processes 6:253-264. https://doi.org/10.1007/ s40710-018-0345-0

Davis JA (2019) Styrofoam Facts - Why you may want to bring your own cup. In: Society of Environmental Journalists. https://www.sej.org/publications/backgrounders/styrofoam-facts-why-you-maywant-bring-your-own-cup Accessed 20 Jul 2021

Franzellitti S, Canesi L, Auguste M, Wathsala RHG, Fabbri E (2019) Microplastic exposure and effects in aquatic organisms: a physiological perspective. Environ Toxicol Pharmacol 68:37-51. https:// doi.org/10.1016/j.etap.2019.03.009

Ho B, Roberts T, Lucas S (2017) An overview on biodegradation of polystyrene and modified polystyrene: the microbial approach. Crit Rev Biotechnol 38:308-320. https://doi.org/10.1080/07388551. 2017.1355293

Jaiswal S, Sharma B, Shukla P (2020) Integrated approaches in microbial degradation of plastics. Environ Technol Innov 17:100567. https://doi.org/10.1016/j.eti.2019.100567

Jung J, Heo A, Park YW, Kim YJ, Koh H, Park W (2014) Gut microbiota of Tenebrio molitor and their response to environmental change. J Microbiol Biotechnol 24:888-897. https://doi.org/10.4014/ jmb.1405.05016

Kim HR, Lee HM, Yu HC, Jeon E, Lee S, Li J, Kim DH (2020) Biodegradation of polystyrene by Pseudomonas sp. isolated from the gut of superworms (larvae of Zophobas atratus). Environ Sci Technol 54(11):6987-6996. https://doi.org/10.1021/acs.est.0c01495

Kingsolver JG (2000) Feeding, growth, and the thermal environment of cabbage white caterpillars, Pieris rapae L. Physiol Biochem Zool 73(5):621-628. https://doi.org/10.1086/317758

Lear G, Kingsbury JM, Franchini S, Gambarini V, Maday SDM, Wallbank JA, Weaver L, Pantos O (2021) Plastics and the microbiome: impacts and solutions. Environmental Microbiome 16(1):219. https://doi.org/10.1186/s40793-020-00371-w

Le Gall M, Behmer S (2014) Effects of protein and carbohydrate on an insect herbivore: the vista from a fitness landscape. Integr Comp Biol 54(5):942-954. https://doi.org/10.1093/icb/icu102

Marsh K, Bugusu B (2007) Food packaging-roles, materials, and environmental issues. J Food Sci 72(3):R39-R55. https://doi.org/10.1111/j.1750-3841.2007.00301.X

Peng BY, Su U, Chen Z, Chen J, Zhou X, Benbow ME, Criddle CS, Wu WM, Zhang Y (2019) Biodegradation of polystyrene by dark (Tenebrio obscurus) and yellow (Tenebrio molitor) mealworms (Coleoptera: Tenebrionidae). Environ Sci Technol 53:5256-5265. https://doi.org/10.1021/acs.est. $8 \mathrm{~b} 06963$

Peng BY, Chen Z, Chen J, Yu H, Zhou X, Criddle CS, Wu WM, Zhang Y (2020) Biodegradation of polyvinyl chloride (PVC) in Tenebrio molitor (Coleoptera: Tenebrionidae) larvae. Environ Int 145:106106. https://doi.org/10.1016/j.envint.2020.106106

Peng BY, Chen Z, Chen J, Zhou X, Wu WM, Zhang Y (2021) Biodegradation of polylactic acid by yellow mealworms (larvae of Tenebrio molitor) via resource recovery: a sustainable approach for waste management. J Hazard Mater 416:125803. https://doi.org/10.1016/j.jhazmat.2021.125803

Plastics Europe (2020) Plastics - The Facts 2020 PlasticsEurope. https://www.plasticseurope.org/application/files/3416/2270/7211/Plastics_the_facts-WEB-2020_versionJun21_final.pdf. Accessed 18 Jul 2021

Rho MS, Lee KP (2016) Balanced intake of protein and carbohydrate maximizes lifetime reproductive success in the mealworm beetle, Tenebrio molitor (Coleoptera: Tenebrionidae). J Insect Physiol 91-92:93-99. https://doi.org/10.1016/j.jinsphys.2016.07.002

Sivan A (2011) New perspectives in plastic biodegradation. Curr Opin Biotechnol 22(3):422-426. https://doi.org/10.1016/j.copbio.2011.01.013

Thaysen C, Stevack K, Ruffolo R, Poirier D, De Frond H, DeVera J, Sheng G, Rochman CM (2018) Leachate from expanded polystyrene cups is toxic to aquatic invertebrates (Ceriodaphnia dubia). Front Mar Sci 5:71. https://doi.org/10.3389/fmars.2018.00071

Tsochatzis E, Berggreen I, Nørgaard J, Theodoridis G, Dalsgaard T (2021) Biodegradation of expanded polystyrene by mealworm larvae under different feeding strategies evaluated by metabolic profiling using GC-TOF-MS. Chemosphere 281:130840. https://doi.org/10.1016/j.chemosphere.2021.130840

Urbenak AK, Mironczuk AM, Rybak J, Wrobel M, Leluk K (2020) A comprehensive assessment of microbiome diversity in Tenebrio molitor fed with polystyrene waste. Environ Pollut 262:114281. https://doi.org/10.1016/j.envpol.2020.114281

Urrejola S, Nespolo R, Lardies MA (2011) Diet-induced developmental plasticity in life histories and energy metabolism in a beetle. Rev Chil Hist Nat 84(4):523-533. https://doi.org/10.4067/S0716078X2011000400005 
van Broekhoven S, Oonincx DGAB, van Huis A, van Loon JJA (2015) Growth performance and feed conversion efficiency of three edible mealworm species (Coleoptera: Tenebrionidae) on diets composed of organic by-products. J Insect Physiol 73:1-10. https://doi.org/10.1016/j.jinsphys.2014.12.005

Verma R, Vinoda K, Papireddy M, Gowda A (2016) Toxic pollutants from plastic waste - a review. Procedia Environ Sci 35:701-708. https://doi.org/10.1016/j.proenv.2016.07.06

Woods AH (1999) Patterns and mechanisms of growth of fifth-instar Manduca sexta caterpillars following exposure to low- or high-protein food during early instars. Physiol Biochem Zool 72(4):445-454. https://doi.org/10.1086/316678

Yang L, Gao J, Liu Y, Zhuang G, Peng X, Wu WM, Zhuang X (2021a) Biodegradation of expanded polystyrene and low-density polyethylene foams in larvae of Tenebrio molitor Linnaeus (Coleoptera: Tenebrionidae): broad versus limited extent depolymerization and microbe-dependence versus independence. Chemosphere 262:127818. https://doi.org/10.1016/j.chemosphere.2020.127818

Yang SS, Brandon AM, Flanagan JCA, Yang J, Ning D, Cai SY, Fan HQ, Wang ZY, Ren J, Benbow EM, Ren NQ, Waymouth RM, Zhou J, Criddle CS, Wu WM (2018a) Biodegradation of polystyrene wastes in yellow mealworms (larvae of Tenebrio molitor Linnaeus): factors affecting biodegradation rates and the ability of polystyrene-fed larvae to complete their life cycle. Chemosphere 191:979-989. https:// doi.org/10.1016/j.chemosphere.2017.10.117

Yang SS, Brandon AM, Xing DF, Yang J, Pang JW, Criddle CS, Ren NQ, Wu WM (2018b) Progresses in polystyrene biodegradation and prospects for solutions to plastic waste pollution. IOP Conference Series: Earth and Environmental Science 150:1-9. https://doi.org/10.1088/1755-1315/150/1/012005

Yang SS, Ding MQ, He L, Zhang CH, Li QX, Xing DF, Cao GL, Zhao L, Ding J, Ren NQ, Wu WM (2021b) Biodegradation of polypropylene by yellow mealworms (Tenebrio molitor) and superworms (Zophobas atratus) via gut-microbe-dependent depolymerization. Sci Total Environ 756:144087. https://doi. org/10.1016/j.scitotenv.2020.144087

Yang SS, Wu WM, Brandon AM, Fan HQ, Receveur JP, Li Y, Wang ZY, Fan R, McClellan RL, Gao SH, Ning D, Phillips DH, Peng BY, Wang H, Cai SY, Li P, Cai WW, Ding LY, Yang J, Criddle CS (2018c) Ubiquity of polystyrene digestion and biodegradation within yellow mealworms, larvae of Tenebrio molitor Linnaeus (Coleoptera: Tenebrionidae). Chemosphere 212:262-271. https://doi.org/10.1016/j. chemosphere.2018.08.078

Yang Y, Yang J, Wu WM, Zhao J, Song Y, Gao L, Yang R, Jiang L (2015a) Biodegradation and mineralization of polystyrene by plastic-eating mealworms: part 1 . Chemical and physical characterization and isotopic tests. Environ Sci Technol 49:12080-12086. https://doi.org/10.1021/acs.est.5b02661

Yang Y, Yang J, Wu WM, Zhao J, Song Y, Gao L, Yang R, Jiang L (2015b) Biodegradation and mineralization of and mineralization of polystyrene by plastic-eating mealworms: part 2. Role of gut microorganisms. Environ Sci Technol 49:12087-12093. https://doi.org/10.1021/acs.est.5b02663

Yang Y, Hu L, Li X, Wang J, Jin G (2021c) Nitrogen fixation and diazotrophic community in plastic-eating mealworms Tenebrio molitor L. Research Square 10.21203/rs.3.rs-627936/v1

Zalasiewicz J, Waters CN, Ivar do Sul JA, Corcoran PL, Barnosky AD, Cearreta A, Edgeworth M, Galuszka A, Jeandel C, Reinhold L, McNiell JR, Steffen W, Summerhayes C, Wagreich M, Williams M, Wolfe AP, Yonan Y (2016) The geological cycle of plastics and their use as a strategic indicator of the Anthropocene. Anthropocene 13:4-17. https://doi.org/10.1016/j.ancene.2016.01.002

Zhou X, Vazquez-Gutierrez JL, Johansson DP, Landberg R, Langton M (2016) Yellow mealworm protein for food purposes - extraction and functional properties. PLoS One 1-17. https://doi.org/10.1371/journ al.pone.0147791

Publisher's Note Springer Nature remains neutral with regard to jurisdictional claims in published maps and institutional affiliations. 